\title{
Characterization of Data Analysis in the Physics Laboratory Among Pre-service Physics Teachers
}

\author{
Ida Kukliansky ${ }^{1}$ \\ ${ }^{1}$ Department of Industrial Engineering and Management, Faculty of Engineering, Ruppin Academic Center, \\ Israel \\ Correspondence: Ida Kukliansky, Department of Industrial Engineering and Management, Faculty of \\ Engineering, Ruppin Academic Center, Israel.
}

Received: August 8, 2019

doi:10.20849/aes.v4i2.630
Accepted: September 9, 2019

Online Published: September 12, 2019

URL: https://doi.org/10.20849/aes.v4i2.630

\begin{abstract}
Establishing the connection between the scientific experiment and theory may pose quite a challenge for learners. Analyzing and interpreting data, they collect in the experiments, helps to bridge the gap between the experiment's results and the theoretical world. The present research examines the barriers pre-service physics teachers confront with when dealing with data analysis tasks in the introductory physics laboratory. Identifying pre-service physics teachers' misconceptions is very important because the future teachers can transfer them to their students. The novelty of this research is not only in identifying the physics teacher's trainee's misconceptions analyzing data in the introductory physics laboratory, but also in explaining the reasons for them. 25 pre-service physics teachers who had undergone several laboratory courses participated in this study. For examining their knowledge level and identifying their difficulties in data analysis, the Laboratory Data Analysis Instrument (LDAI) was used. The results revealed that the participants evidenced a sixty-nine percent overall average of correct answers. The various misconceptions the pre-service physics teachers encountered in each of the instrument objectives are identified and discussed. Dealing with multiple representations and the use of intuitive rules can explain some of the difficulties. The identification of the data analysis difficulties can be employed by educators attempting to construct more efficient learning environments.
\end{abstract}

Keywords: intuitive rules, misconceptions, multiple representations, physics laboratory, pre-service physics teachers

\section{Introduction}

The physics laboratory is essential studying physics on different levels. In order to extract meaning from experimental laboratory data and build scientific explanations based on it, understanding of analyzing experimental data, both on conceptual and procedural levels, is important (Bowen \& Roth, 2005; Rollnick, Zwane, Staskun, Lotz \& Green, 2001). Data analysis process is crucially needed in the effort of bridging the gap between the data, collected in the experiments conducted in the laboratory, and the physics theories learned in the physics classes. Lacking the required skills to analyze data, the inexperienced and immature learner might become confused in the thicket of raw data, and be unable to reach the required conclusions (Ausubel, 1968).

In spite the fact that data analysis is important and students in the physics' laboratory need to possess the appropriate relevant skills, according to the literature, data analysis in the physics' laboratory pose a challenge for students (e.g. Allie at al., 2003; Eshach \& Kukliansky, 2016; Kung, 2005; Pillay, Buffler, Allie \& Lubben, 2008). These skills include considering errors and uncertainties as well as graphing skills such as choosing the appropriate graph to present data, calculating and adding error bars and regression lines, and understanding scientific information from the graph (Eshach \& Kukliansky, 2016). On one hand, sometimes the student's misconceptions are the same as their teacher's one (Abell, 2007), so identifying misconceptions of in-service teachers in general and pre-service teachers in particular is crucial to better understand the ones of students'. On the other hand, the general assumption in many studies regarding student's difficulties is that their teachers possess the needed knowledge and can provide explanations, diagnose errors made by students and understand non-standard but correct procedures (Kaltakci-Gurel, Eryilmaz \& McDermott, 2016). Indeed, pre-service physics teachers' are expected to be proficient not only in content knowledge and pedagogical knowledge, but also in pedagogical content knowledge (Etkina, 2010) meaning that they are required not only to know the required 
topics by themselves and know how to teach in general, but also to have the knowledge regarding the relevant students' difficulties and misconceptions in the topics they teach. This is very important in teaching adaptively and using student centered teaching approach (Ostermann, Leuders \& Nückles, 2017).

However, it seems that pre-service teachers also suffer from lack of knowledge regarding a variety of physics concepts such as mechanics (Bayraktar, 2009), electricity (Dinçer \& Tuğbanur, 2017), optics ( Kaltakci-Gurel, Eryilmaz \& McDermott, 2016), astrophysics (Steinberg \& Cormier, 2013) and relativity theory (Selçuk, 2011). Although laboratory plays important role in physics education there is, to much less extent, research on pre-service physics teachers regarding their understanding concerning relevant topics related to the laboratory. What mostly exists in the literature focuses on the attitudes towards the laboratory, to inquiry based teaching and to planning the practical work in the laboratory (e.g. Marshall \& Dorward, 2000; Nivalainen, Asikainen \& Hirvonen, 2010, 2013; Palic \& Pirasa, 2012). The present research sought to fill this gap and it examines the barriers pre-service physics teachers confront with when dealing with data analysis tasks in the laboratory. Identifying pre-service physics teachers' misconceptions is very important because the future teachers can transfer them to their students while their intuitive conceptions overshadow their pedagogical content knowledge (Gvozdic \& Sander, 2018). The novelty of this research is not only in identifying the physics teacher's trainee's misconceptions analyzing data in the introductory physics laboratory, but also in explaining the reasons for them.

\section{Methods}

\subsection{Participants}

Due to lack of physics teachers in Israel, the Israeli education Ministry established a program to requite people who hold B.Sc. degree in physics or engineering, with good marks, for a one year program preparing them to become physics teachers. The participants got a scholarship for their studies. 25 participants of this study took part in this program. All of the participants had taken physics laboratory classes in the framework of this program, in addition, of course, to the at least 4 laboratory classes that they took during their B.Sc. studies.

\subsection{Research Tool}

For examining the participant's knowledge level and identifying their difficulties in data analysis, the Laboratory Data Analysis Instrument (LDAI) was used. The detailed description of this instrument, including the questions in the questionnaire (Eshach \& Kukliansky 2016). Its validity and reliability was established by seven experts and the pilot study. The LDAI is a student-centered instrument, meaning that the distracters to the questions were taken from both literature and interviews with students. Furthermore, students were allowed, in an open-ended format, to articulate whatever idea they deemed representative of their viewpoint on the target issue. In some of the questions the participants were asked to explain their choice. The LDAI instrument provides the participants with a lab report - an effective step by step description of an experiment based upon Newton's second law. It then walks the participants through the process of conducting the experiment, asking them to make the necessary decisions along the way.

The tool is unique in that the 30 questions are embedded throughout a laboratory report. In this way two things were achieved. First, to ensure that all perspectives and stages relevant to laboratory data analysis were covered; by inserting questions throughout the report, reference to all the experiment's stages was ensured - starting from the nature of measurements and the need for repeating measurement to the representation of data, to complex data analysis such as treating outliers and drawing regression lines. Second, it enabled to ask the questions in the context of the laboratory. The fact that the questions belong all to the context of a laboratory report makes the LDAI a single-context based instrument fulfilling the following conditions: each individual question presents a situation belonging to a specific context and the questions as a whole create a typical case belonging to a specific context. The LDAI relates to the following objectives: (A) central tendencies-5 questions, (B) systematic and random errors and uncertainness-12 questions, (C) graph representations and aims of experiments- 8 questions and (D) regression line fit-5 questions.

\section{Results}

\subsection{General Results}

The reliability coefficient of the instrument was calculated, using Cronbach's Alpha. For each question, a correct answer was marked as 1 and a wrong answer as 0 . The resulting coefficient was 0.815 . The participants scored an overall $69 \%$ average of correct answers. The averages and standard deviations of the percentages of correct answers by the four objectives are presented in Table 1. The highest scores (87\%) were obtained for Objective A's questions and the lowest (35\%) for Objective D's questions. 
Table 1. Summary of the correct answer's score (\%) by the objectives

\begin{tabular}{llc}
\hline Objective & M & SD \\
\hline A:Central tendency measures & 85 & 19 \\
\hline B: Experiment errors and uncertainness & 74 & 15 \\
\hline C: Graphs and aims & 72 & 24 \\
\hline D: Fitting regression lines & 35 & 24 \\
\hline Total & 69 & 12 \\
\hline
\end{tabular}

Figure 1 presents the knowledge levels of the participants by the objectives and for the whole questionnaire. The percentage of participants having grades below $60 \%$, between $60 \%$ and $80 \%$ and above $80 \%$ in each of the four objectives and in the entire questionnaire can be seen in this figure.

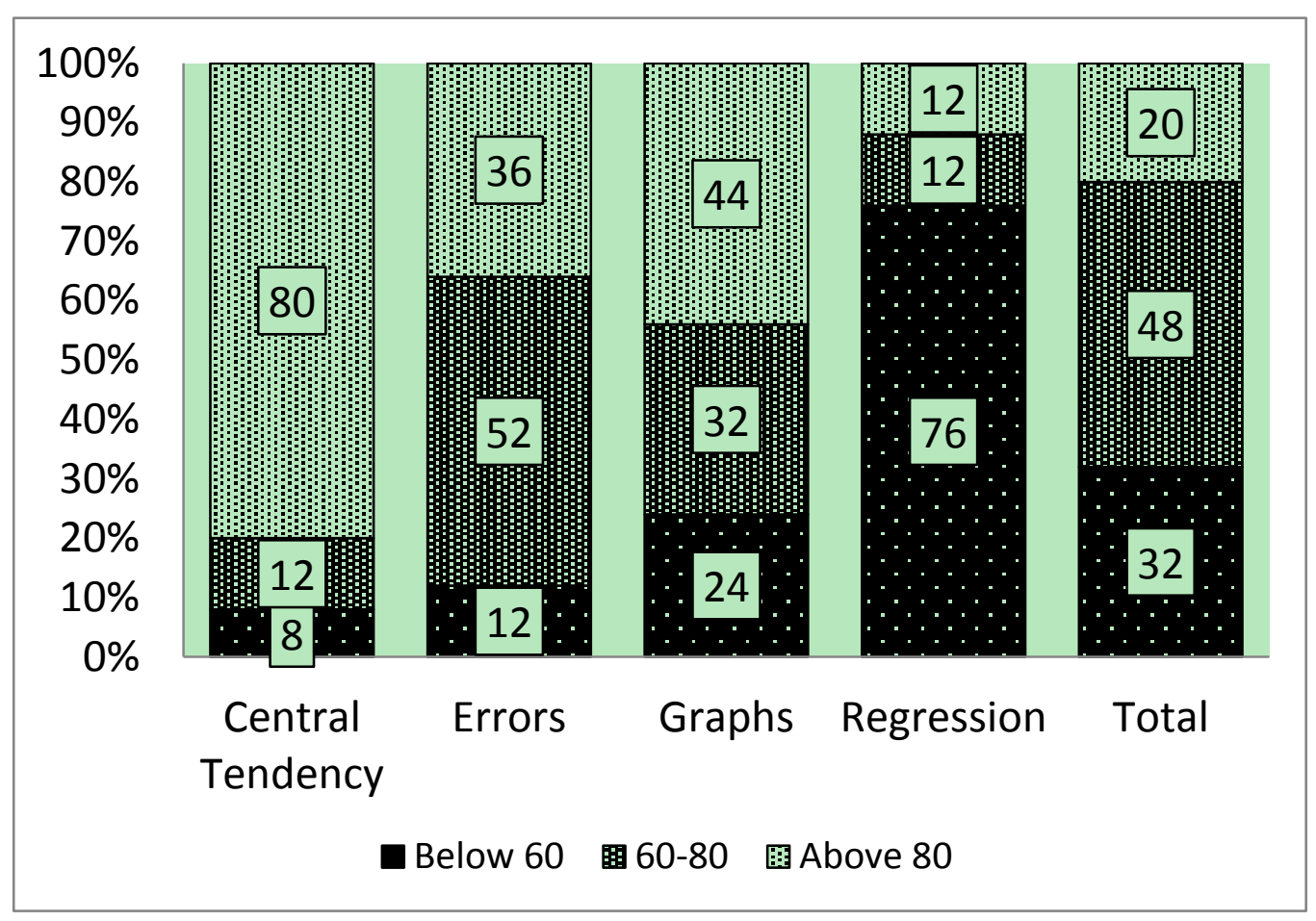

Figure 1. The percentage of participants by knowledge levels for the different objectives and for the whole questionnaire

The assumption of normal distribution of scores (\%) for the different objectives was ruled out using the non-parametric Shapiro-Wilk test ( $\mathrm{W}=0.76$ for Objective A's questions, $\mathrm{Z}=0.82$ for Objective B's questions, $\mathrm{W}=0.88$ for Objective C's questions, $\mathrm{Z}=0.90$ for Objective D's questions, ${ }^{*} \mathrm{p}<0.05$ for all the objectives). Therefore, non-parametric methods were implemented. The Friedman non-parametric test for related samples was used, showing a significant overall difference among the correct responses scores for the four objectives $\left(\chi^{2}(3)=35.43\right.$, *** $\left.\mathrm{p}<0.001\right)$. Post hoc multiple comparisons showed that there were no significant differences between the means of objectives A, B, C, while correct answers score (\%) for Objective D was significantly lower $(* * * \mathrm{p}<0.001)$.

Let us now refer to the difficulties that the participants had in each of the objectives. 


\subsection{Objective A: Knowledge and Understanding of Central Tendency Measures}

As can be seen in Table 1, the average of correct answers in this category was $85 \%$. This relatively high percentage of the correct answers is not surprising as central tendency measures and especially averages are learned as early as in middle school and therefore, participants have relatively a lot of experience with such measures. However, this score was not as high as could be expected. The pre-service teacher's difficulties in this category were:

\subsubsection{Lack of Understanding of Why the Average Measure Was Used and What Factors Affected it}

An example of this difficulty is illustrated in the question: "What measure do you recommend using to determine the acceleration?" The following choices were given: average, maximal measurement, minimal measurement, last measurement, or none of the above. The correct answer is "average", which takes into account all of the measurements, but $12 \%$ of the participants gave incorrect answers. One of them preferred the last measurement, stating that "When taking the last measurement we will be experienced and precise". Another participant who suggested using the maximal measurement explained that "The rate of error for the maximal measurement is the lowest". In another question which examined the influence of adding a sixth measurement equal to the average of a given set of five, $8 \%$ did not know that the average would remain unchanged. The justifications given by participants whose answers were wrong: "The average will change because every addition of measurements changes the grand average"," You add a value equal to the average and divide by 6 this time, and the average will therefore decrease".

\subsubsection{Lack of Understanding of the Need for Repeating Measurements}

A question where the participants were asked to determine the purpose of repeating measurements was particularly difficult for some them. $16 \%$ of them didn't know that repeating measurements are needed for increasing the results' accuracy. $8 \%$ of the participants saw the only purpose of repeating measurements as calculating the average. The frequent usage of the average measure, sometimes mechanically, without understanding the reasons for computing it, may lead to view its computation as the end instead of the means (Eshach \& Schwartz, 2002). The above authors also argue that sometimes students compute the average "just in case". This may also explain why some participants chose this answer. $8 \%$ stated that repeated measurements are necessary only for estimating the spread of the measurements. This may show that computing the spread is considered as the aim.

\subsection{Objective B: Knowledge and Understanding of Experiment Errors and Uncertainness}

As can be seen in Table 1, the average of correct answers for this important objective was $74 \%$. The pre-service teacher's difficulties in this category were:

\subsubsection{Lack of Understanding of the Essence of Random and Systematic Error}

Although the most of the participants could distinguish between systematic and random errors, lack of understanding of their meaning was revealed. For instance, in a question which tested the understanding of random error, $16 \%$ of the participants did not know that a larger random error represented the bigger variability of the experiment's measurements around the average. Instead, they thought that there is no connection between the random error and the spread of the measurements.

In another question participants were required to compare random errors in different situations. For this purpose two sets of 6 acceleration measurements were provided: Set (1) for student A: 2.47, 2.48, 2.49, 2.50, 2.51, 2.52; and Set (2) for student B: $2.47,2.47,2.47,2.52,2.52,2.52$. In this question, demanding a high level of understanding, the average and range of both data sets are identical, but the standard deviation (and therefore the random error $\frac{\sigma}{\sqrt{n}}$ as well) is different. Comparing between the sets, as is necessary in this case, requires one to understand what error means. Only $48 \%$ of the participants managed to correctly determine that the random error for student B was higher; $4 \%$ decided that the random error for student A was higher; $28 \%$ stated that the random errors were the same because the averages were the same, and $20 \%$ stated that the random errors were the same because the number of measurements was the same. This question requires the skill of comparing the variability of a certain distribution, in relation to the same range uniform distribution. The skill of comparing the spread of a certain distribution in relation to the same range uniform distribution aids in estimating the experiment's 
measurements reliability.

\subsubsection{Lack of Understanding of the Influence of Changes in Data on Random Error}

Sometimes a systematic error occurs in the experiment and it is important to estimate its influence on the random error. A lack of understanding was found regarding the influence of systematic error, where the same influence affects the result for each of the repeated measurements, on random error. The reason that in this case the random error remains unchanged is that the difference between all the measurements and their average remains unchanged, so there is no change in the variability. This information is important when conducting lab experiments when a systematic error is discovered and its effect on the average and random error needs to be taken into consideration. It is worthy to refer, in this regard, to another question belonging to objective A. While $20 \%$ of the participants made a mistake in question about estimating how the systematic errors would affect the measurements' average in Objective A, 32\% did not know that systematic errors do not affect the random errors in Objective B. This indicates that pre-service teachers find it easier to estimate the influence of data changes on the average than on random error.

Another question, dealing with the effect on the random error of adding an acceleration measurement equal to the average of the previous 5 measurements, was hard for some of the subjects to answer. $32 \%$ did not know that the random error would decrease. In comparison, in another question, which was related to the average acceleration, only $8 \%$ did not know what the effect of such changes on the average would be. This difference suggests that understanding of the properties of the average is easier than those of random error. Regarding the participants' justifications for their (wrong) answers, these can be divided into two types: (a) The incorrect answer that if the average is unchanged, the random error will be unchanged too and (b) The incorrect answer that if the number of measurements increases, another measure must increase as well. A typical explanation for type (a) was: "The random error is composed of the average acceleration, and therefore, it doesn't change because the average acceleration doesn't change." and a typical explanation for type (b) was: "As the number of times of repeating the experiment goes up so does the random error".

\subsubsection{Lack of Procedural Knowledge}

In one of the questions, the participants were asked to identify the mathematical expression of the random error. Only $68 \%$ of the subjects correctly identified it. The reason for it may be that the pre-service teachers in laboratories were only required to note the random error's value based on the computer's output (using Excel) and not to compute it by themselves. We regard this as a major explanatory factor for this mistake.

A very serious problem of misunderstanding was found in a question, where the participants were asked to calculate the error of a system's mass in an experiment, based on previously received information. Only $12 \%$ of the participants answered correctly. Most of the participants did not take into account all of the factors affecting the error, discounting elements such as the weights' weight, or considering the weight of only one instead of all 6 weights.

\subsection{Objective C: Graphs and Understanding the Relation Between the Experiment's Purpose and the Data's Graph Representations}

The average score for this objective was $72 \%$ correct answers. Student difficulties in this objective were:

\subsubsection{Difficulties to Interpret Graphs}

Interpretation of graphs in this study includes calculating the distance between two points on the graph, not understanding what axes stand for, tendency to attribute a linear behavior, and treating the graph as a picture.

In one question which assumed that each of the graphs represented movement of a body, comparison of accelerations in different points was required. About one third (32\%) of the participants answered (incorrectly), being unable to correctly work out the acceleration in the distance-as-a-function-of-time graph. About a quarter of the participants $(24 \%)$ failed an even simpler task - that of finding the distance the cart moved between the two time points.

In another question, the participants were asked to decide which of the three graphs was best suited for describing the distance, as a function of time, a cart with a weight attached to it via a pulley traveled. $72 \%$ of the participants correctly chose the parabola (correct answer), while $28 \%$ chose the linear graphs (incorrect answers). A possible explanation is the wrong conception that a body on which a constant force is acting will move at a constant velocity. Therefore, the participant treats the movement at constant velocity where the distance is linear, and not the movement with constant acceleration. Another possibility is the tendency to apply a linear behavior to different physical phenomena since usually learners are exposed to such phenomena. 
In one of the questions, the participants were asked to determine whether in one of the graphs at point $\mathrm{B}$ the basket is higher, relative to the floor, than at point A. $20 \%$ of the participants answered wrongly. It is possible that this mistake arose from not interpreting the graph as an abstract schematic representation, but instead, interpreting it as a kind of "picture," where the graph's height represented the actual height of the moving cart. Thus, one may have arrived at the wrong conclusion that in a graph of distance as a function of time, a rise in the graph describes also the rising of the moving body.

\subsubsection{Problems in Extracting the Slope and Understanding Its Meaning}

In one of the question the formula: $a=\frac{g m}{m+M}$ was given with explanations and the following instructions: the chosen graph presents a as a function of mg. The participants were asked to determine what the slope of the chosen graph represented. The answers' distribution was as follows: (a) The system's mass - 8\%; (b) 1 divided by the system's mass (correct answer) - 72\%; (c) 1divided by the basket's weight (including the weights inside) $16 \%$; (d) g- $4 \%$. It can be seen that even though the chosen graph's type was explicitly mentioned and the relevant formula was provided, still, more than a quarter of the participants couldn't correctly determine the meaning of the graph's slope.

\subsubsection{Problems in Fitting the Graph Appropriate to the Experiment's Aim}

In one question the participants were asked to choose the graph addressing the experiment's aim. The distribution of the answers was: a) Graph $\mathrm{M}$ as a function of $\mathrm{a}(4 \%)$; b) The gravity force acting on the basket $\mathrm{mg}$ as a function of $\mathrm{m}+\mathrm{M}$ (the system's mass) (28\%); c) a as a function of the gravity force acting on the basket $\mathrm{mg}(68 \%$, the correct answer); d) The gravity force acting on the basket $\mathrm{mg}$ as a function of $\mathrm{g}(0 \%) .32 \%$ of the participants chose the wrong graphs. In this same question, the participants were also requested to justify their answers. Below, the wrong justifications for the a) and b) choices are presented:

a) Graph $\mathrm{M}$ as a function of $\mathrm{a}$ - The explanation below indicates that the participant was confused regarding the mass to which he referred. The participant was thinking of Newton's 2nd law but did not recognize the fact that in this experiment the system's mass remained constant and only mg changed. "The formula of Newton's 2nd law is $\mathrm{F}=\mathrm{ma}$, and we're checking the effect of the mass on the force." The participant treated the formula in a general manner and didn't check its purpose in this particular experiment. Meaning, the participant did not understand the meaning of the system's mass.

b) The gravity force acting on the basket mg as a function of $\mathrm{m}+\mathrm{M}$ (the system's mass) - Those who chose this answer did not understand that $\mathrm{m}+\mathrm{M}$ was constant throughout the whole experiment and chose the graph which presented the gravity force variable as a function of a constant. An example: When $m g=a(m+M)$ then the slope is $(\mathrm{mg} \Leftrightarrow \mathrm{y} ;(\mathrm{m}+\mathrm{M}) \Leftrightarrow)=>\mathrm{a}=$ constant. Here the participant considered only the graph's form but did not understand that $\mathrm{m}+\mathrm{M}$ was constant.

\subsection{Objective D: Fitting a Regression Line to the Measurements}

This objective included questions which examined fitting a regression line to the measurements. It was especially difficult for the participants with an average of only 35\% correct answers - a significantly lower average than the ones of the other objectives. The difficulties in this objective were:

3.5.1 Lack of Understanding That the Regression Line Is an Optimal Line Minimizing the Sum of Squares of All the Vertical Deviations to the Line From All the Data Points

An essential stage of laboratory work is applying a regression line to the measurements obtained during the experiment. This is usually done using the "Least Squares" method. According to this method the optimal line brings to a minimum the sum of squares of all the vertical deviations from all the points until the line. Using this method ensures that the point of the average will be on the line itself. A common misconception found in the present study - for $48 \%$ of the participants - was to minimize the sum of squares of the distances of the points from the line. Less than half of the participants (44\%) fully knew how to apply the "Least Squares" method. While minimizing the sum of the squares of the distances from the line gives a symmetrical role to both variables, minimizing the sum of squares of all the vertical deviations enables arriving at an optimal forecast of $\mathrm{Y}$ given $\mathrm{X}$. One of the consequences of this misconception is not distinguishing between the dependent variable and the explanatory variable.

3.5.2 Lack of Understanding of How to Treat Points That Are "Far" From the Regression Line as well as the 


\section{Meaning of "Far"}

A question that examined the handling of outliers while fitting a regression line to the measurements, yielded only $32 \%$ correct answers. To correctly answer this question, the relation between the measurements and the calculated regression line (based on the "least squares" method and drawn as a graph) needs to be understood. The concept 'error bar' and its graph representation must be known as well. If a measurement's error bar does not cross the fitted regression line, the measurement is an outlier and should be ignored. The correct choice for this question was considering point $\mathrm{B}$, found within the error bar of the regression line, and re-measuring point $\mathrm{A}$, which was outside the error bar (at the first physics laboratory level participants should refer to the error bar). The pre-service teachers' percentages and justifications are presented below.

Ignoring both points when constructing the graph (52\%): The common element in the explanations for this proposition was that participants tended to "discard" deviant measurements without deeply considering whether these were really deviant. Some of the participants saw no difference between the two points, such examples include: "Probably the two points do not represent the connection I was looking for and therefore I will ignore them."; "It is possible that an error occurred in these points."; "The measurements are far off and do not represent the rest of the measurements, they just decrease the graph's exactness."; and "They are both equally unsuitable and therefore one should not preferred over the other." Some participants thought that the errors cancel each other out: "Neutralizing deviations. The errors are in different directions and cancel each other out" and "The errors are from both sides of the line and I would therefore ignore them - they do not point at a non-random error." Only one of the explanations indicated that the student understood the difference between the two points: "I would discard the points because with 5 trials a conclusion can be reached. If there were less trials I would discard A and re-check B."

Perform an additional measurement for situation B but not for situation A $(0 \%)$ : Nobody chose this answer.

To consider both points $A$ and $B$ when constructing the graph (16\%): Those who chose this proposition were not willing to give up any of the experiment's measurements. Some pointed out that the fact that the two points were found on both sides of the line made their choice easier, while some emphasized that using $R^{2}$ will account for the error: "Because this is a measurement obtained in the experiment and there is no point in hiding such data, this way the results will be reliable."; "The $\mathrm{R}^{2}$ correlation coordinator will account for this error in its answer." (This answer supports not understanding the meaning of $\mathrm{R}^{2}$ ) and "Maybe they describe a phenomenon which should not be ignored. Maybe Newton's 2nd law is not true - this is what we are checking!" (This relates also to the previous point regarding the lack of understanding of the relation between theory and experiment).

To conduct another measurement for point $A$ but not for B (32\%): Pre -service teachers who chose this proposition knew the error bar term and used it correctly. A typical answer was: "A is outside the error bar range, B is in it."

\subsubsection{Lack of Understanding the Meaning of $\mathrm{R}^{2}$}

Most of the participants did not know that in addition to the line's equation, $\mathrm{R}^{2}$ had to be taken into account as well, what would allow judging the degree of suitability of the line to the measurements obtained in the experiment. The closer this measure is to 1 the stronger is the relation between the variables, and therefore, the measurements are closer to the applied regression line. A student who is unaware of this might think that the regression line appropriately represents the measurements even when this is not the case. Two of the questionnaire's questions dealt with the understanding of this important concept. In one of them, only $44 \%$ knew that getting a low $\mathrm{R}^{2}$ in the experiment necessitated repeating the measurements because they were not accurate, while most of the participants $(56 \%)$ thought that a low $\mathrm{R}^{2}$ in the experiment indicated, necessarily, that a nonlinear relation between the cart's acceleration and the gravity needed to be considered. This indicates a lack of understanding of the relation between theory and experiment as, obviously, Newton's 2nd law is in operation. This said, it is important to note that apart from gravity there might be frictional forces at play which may scale with $\mathrm{v}$ or $\mathrm{v} 2$, which should either be decreased in repeating the measurements, or be taken into account when searching for non-linear relationships (this might be beyond the aims of the introductory laboratory).

The other question examined the understanding of the $\mathrm{R}^{2}$ concept. Even though the participants were required to use this expression in their lab reports when fitting the regression line, only $32 \%$ chose the correct answer for this question. The findings revealed that most of the participants indeed used $\mathrm{R}^{2}$ in their reports without really knowing what it represented.

The results show that the participants, for the most part, knew how to carry out the technical task of obtaining the regression equation and $\mathrm{R}^{2}$ as a computer program's output, however, they did not have a deeper knowledge 
regarding the analysis method and meaning of the results.

3.5.4 Lack of Understanding That Measurement Errors Can Cause the Regression Line to Deviate From the Theoretical Line

One of the questions regarded the effect of measurement errors on the regression line. In this question the applied acceleration line as a function of the gravitational force (provided to the participants) didn't pass through the point of origin. The pre-service teachers were asked to explain the reason for this. It turned out that $40 \%$ of the participants did not understand that measurement errors could cause the regression line to deviate from the one which should have been theoretically arrived at $24 \%$ of them thought that Newton's second law relates not to real but to ideal systems, $12 \%$ thought that there was a mistake in calculating the line's equation, and $4 \%$ thought they had to repeat the measurements in order to calculate the proper line.

\section{Discussion}

The way data is processed and turned into knowledge as a cornerstone of science (Allie \& Demaree, 2010). Indeed, recent years have evidenced a shift in emphasis in learning and instruction from the acquisition of basic skills and large amounts of information to deep understanding and development of reasoning skills, as these latter skills are those that enable to acquire and process new knowledge (Zohar \& Ben-David, 2008).

The present study which focuses on pre-service physics' teachers' data analysis abilities is part of this trend. The aim of the present research was to examine whether and to what extent are pre-service physics teacher trainees, competent in data analysis skills required for creating meaning out of raw experimental data, and drawing connections between data and scientific explanations, on the level required in the introductory physics laboratory. To accomplish this goal, the raw data analysis tool LDAI was used. Four issues were the focus of our research: central tendencies, error (uncertainty and systematic), graph presentation, and regression line fit. The results of the study indicated an average score $(69 \%)$, one lower than what could be expected from pre-service teachers. Differences in levels of understanding were found between different objectives and within objectives. Relatively higher marks were scored in the 'central tendency measures' objective in comparison to other objectives. Very low scores were obtained in the 'applying a regression line to the measurements' objective. In the results section we detailed the difficulties that participants evidenced in each objective.

Abstracting facts to form scientific explanations does not follow from simple observation and experience of the world. Rather, as Bowen and Roth (2005) state: "Physical phenomena are translated through consecutive inscriptions that may include, in increasing order of complexity, such re-presentations as maps, lists, tables, totals, means, graphs and equations" (pg. 1064). In addition, in the process of developing theories, scientists also manipulate the data translating one representation into another. Translations between representations and transformations within representations demonstrate a deeper level of understanding and the emergence of critical thinking skills (Mallet, 2007). However, working within a multi-representational learning environment may pose a challenge for learners. According to van der Meij and de Jong (2006), such environments require: (1) understanding the syntax of each of the representations, (2) understanding which part of the topic is being represented, (3) identifying partial correspondence between representations, and (4) translating between representations by finding the similarities and differences in the two systems of representation. Apparently, according to Ainsworth (1999) it is difficult to tie together different representations of the same topic and the translation process between representations is not an easy one for learners (Dori \& Sasson, 2008). Indeed, information selection and organization, parsing of symbol structures, mapping of analog structures as well as model construction and model inspection are required for construction of mental representations while analyzing graphical representations (Schnotz \& Bannert, 2003) needed in the laboratory data analysis.

The cognitive challenge in the process working with laboratory data (e.g. manipulating raw data, simultaneously representing it in a variety of forms, moving from one representation to another) may explain the difficulties identified in this study which also concur with other studies conducted regarding the handling of multiple representations simultaneously (e.g. Arcavi, 2003). For instance, the interpretation of a graph as being a kind of picture might be due to the difficulty to 'translate' the distance-time graph to a real life situation, instead making parallels between the basket's height and the graph's height. Also, the difficulty to extract the acceleration measure from a graph describing distance as a function of time stems, probably, from the difficulty to extract a numerical value from a visual representation. Indeed, in order to extract the acceleration one has to 'translate' the graph's slope and tie it to acceleration. In addition, the difficulty to choose the graph that best describes the distance the cart traveled during the experiment as a function of time may stem from the difficulty to conduct the sequential translations this task demands: translating the distance traveled by the cart as a function of time to an analytical representation - a formula - and then translating it again from the formula to the description of the 
correct graph. This process is illustrated in Figure 2 below.

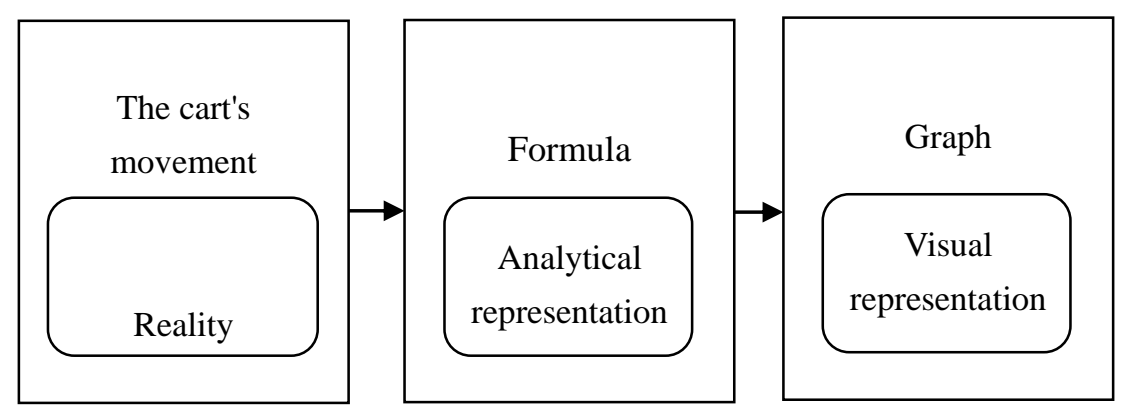

Figure 2. The translation process in choosing the graph

About a fifth of the participants made mistakes and chose wrong linear graphs. A possible explanation for this choice is that the participants were influenced by the movement which took place on a straight horizontal plane, and consequently, chose a graph which included straight lines. Again, this attests to pre-service teacher's difficulties in translating information from one representation to another. About a fourth of the participants experienced difficulties in questions requiring the reading of kinematics graphs, in which visually represented information needed to be translated to a numerical representation. For example, calculating the distance traveled by the cart during time interval specified by two time points. The difficulties revealed in these questions accord with the results of numerous studies of kinematic graph representation in physics (e.g. Beichner, 1994; Forster, 2004) and in the physics lab in particular (Ivanjek, Susac, Planinic, Andrasevic \& Milin-Sipus, 2016; Nixon, Godfrey, Mayhew \& Wiegert, 2016). Another example demonstrating the need, and therefore the difficulty, of dealing simultaneously with three different visual representations was a graph which included a scatter diagram describing the results of the experiment's measurements, the regression line which was calculated and drawn between the points, and the error bar which was calculated and marked around each of the points. The question dealt with the handling of deviant measurements - measurements relatively far from the measurements' regression line. The participants were asked whether, when applying the regression line, two relatively distant points (from the regression line) needed to be taken into account. One of the points was within the range of the error bar and one was not. Visual considerations alone might have led to ignoring the two points because they were "too distant" from the line which passed through all the other points. Visual considerations might have also lead to the points being taken into account and to the decision that the regression line should be affected by them. The majority of the participants (over 70\%) chose one of these two wrong options. The correct answer in this case was that the point within the error bar needed to be included, while the one outside the error bar had to be re-measured. It seems that participants were excessively challenged by the need to deal with three representations simultaneously and thus considered only two of them - the scatter diagram and the regression line - disregarding the error bar. On the other hand, the explanations of the participants revealed that they understood the meaning of the error bar. Moreover, it seems that the participants were influenced by purely superficial visual considerations - how far the scattered points were in relation to the regression line. This process is presented in Figure 3. 


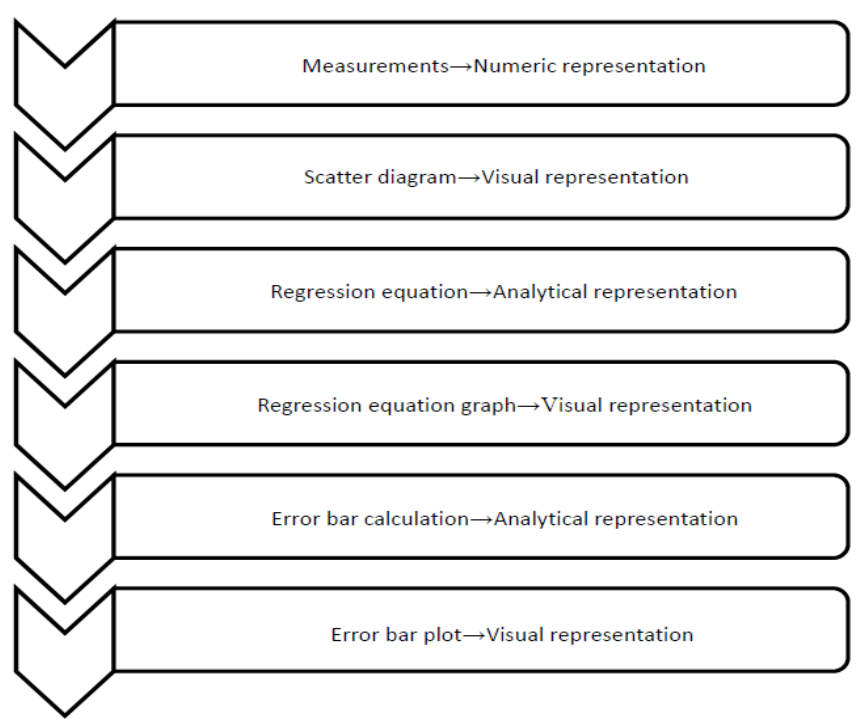

Figure 3. The translation process dealing with three visual representations

Another possible explanation for some misconceptions of the pre-service teachers in dealing with experimental data can be attributed to the use of the intuitive rules. The intuitive rules theory is a broad theoretical framework providing insights regarding learners' conceptions in a variety of domains in both science and mathematics. According to this theory people of different ages, use the intuitive rules More A-More B and Same A - Same B in the process of comparing of two quantities A and B (Stavy et al., 2006; Tirosh \& Stavy, 1999;). The results of this study support the findings that some of the difficulties in dealing with errors and uncertainties requiring comparison tasks can stem from the use of intuitive rules (Eshach \& Kukliansky, 2018). For example, in a question that was described in the Results section, Objective (B), $48 \%$ gave wrong answers that can be explained by the use of the intuitive rule Same A-Same B. $28 \%$ decided that the random errors were the same because the averages were the same, and $20 \%$ decided that the random errors were the same because the number of measurements was the same. Another question in the Results section Objective (B), was dealing with the effect of adding an acceleration measurement equal to the average of the previous 5 measurements, on the random error. $28 \%$ of the participants thought that the random error will increase. One of the explanations was "if we make more measurements, we make more errors, so the random error will increase". This mistake may stem from using the intuitive rule More A-More B.

Moreover, the intuitive rules theory can be applied as a conceptual framework for understanding why some of the misconceptions in reading graphs in physics occur (Eshach, 2014), explaining some of the difficulties of the participants of our study in reading graphs.

\section{Conclusion and Implication of the Study}

The present study's aim was to expose pre-service teacher's difficulties in treating laboratory data analysis and to explain the reasons for them. As the results showed, for developing more quality teachers, there certainly is room for improvement in pre-service teachers' data analysis skills. It is probably unrealistic to expect from the pre-service teachers' to spontaneously develop the full range of necessary data analysis skills in laboratory classes. Educational programs for pre-service physics teachers should take into account conceptual barriers such as those detailed in this study. Laboratory learning environments must address such difficulties and deal with them. Expecting that learners will develop appropriate data analysis skills, without at least a short briefing, is impractical, therefore pre-service physics teachers' courses should be designed in order to overcome their misconceptions Our recommendation is to use learning units like the one described in Kukliansky \& Eshach (2014), which will systematically impart data analysis skills before the entering the laboratory. Such a unit, utilizing the learning in context approach, where both procedural and conceptual knowledge were given emphasis, can help the educators in building better learning environments for the pre-service physics teachers in order to improve their laboratory data analysis skills and provide a better knowledge base to their future students. 


\section{References}

Abell, S. K. (2007). Research on science teacher knowledge (Chapter 36). In S.K. Abell \& N.G. Lederman (Eds.), Research on Science Teacher Education (pp. 1105-1149). New York: Routledge.

Ainsworth, S. (1999). The functions of multiple representations. Computers \& Education, 33(2-3), $131-152$. http://doi.org/10.1016/S0360-1315(99)00029-9

Allie, S., \& Demaree, D. (2010). Toward meaning and scientific thinking in the traditional freshman laboratory: Opening the "idea space." AIP Conference Proceedings, 1289, 1-4. https://doi.org/10.1063/1.3515198

Allie, S., Buffler, A., Campbell, B., Lubben, F., Evangelinos, D., Psillos, D., \& Valassiades, O. (2003). Teaching measurement in the introductory physics laboratory. The Physics Teacher, 41(7), 394-401. https://doi.org/10.1119/1.1616479

Arcavi, A. (2003). The role of visual representations in the learning of mathematics. Educational Studies in Mathematics, 52, 215-241. https://doi.org/10.1023/A:1024312321077

Ausubel, D. (1968). Educational psychology: A cognitive view. New York: Holt, Rinehart \& Winston.

Bayraktar, S. (2009). Misconceptions of Turkish pre-service teachers about force and motion. International Journal of Science and Mathematics Education, 7(2), 273-291. https://doi.org/10.1007/s10763-007-9120-9

Beattie, G., Shovelton, H., Blindern, P. O., Duit, R., Treagust, D., Givry, D., \& Driver, R. (2006). An experimental investigation of some properties of individual iconic. Cognition, 43(2), 1086-1109. https://doi.org/10.1002/tea

Beichner, R. J. (1994). Testing student interpretation of kinematics graphs. American Journal of Physics, 62(8), 750-762. https://doi.org/10.1119/1.17449

Bowen, G. M., \& Roth, W. M. (2005). Data and graph interpretation practices among preservice science teachers. Journal of Research in Science Teaching, 42(10), 1063-1088. https://doi.org/10.1002/tea.20086

Eshach, H. (2014). The use of intuitive rules in interpreting students' difficulties in reading and creating kinematic graphs. Canadian Journal of Physics, 92(1), 1-8. https://doi.org/10.1139/cjp-2013-0369

Eshach, H., \& Kukliansky, I. (2016). Developing of an instrument for assessing students' data analysis skills in the undergraduate physics laboratory. Canadian Journal of Physics 94(11), 1205-1215. https://doi.org/10.1139/cjp-2016-0308

Eshach, H., \& Kukliansky, I. (2018). University Physics and Engineering Students' Use of Intuitive Rules, Experience, and Experimental Errors and Uncertainties. International Journal of Science and Mathematics Education, 16(5), 817-834. https://doi.org/10.1007/s10763-017-9817-3

Eshach, H., \& Schwartz1, J. L. (2002). Understanding children's comprehension of visual displays of complex information. Journal of Science Education and Technology, 11(4), 333-346. https://doi.org/10.1023/A:1020690201324

Etkina, E. (2010). Pedagogical content knowledge and preparation of high school physics teachers. Physical Review Special Topics - Physics Education Research, 6(2), 1-26. https://doi.org/10.1103/PhysRevSTPER.6.020110

Forster, P. (2004). Examinations in Western Australia. Research in Science Education, 34(3), $239-265$. https://doi.org/10.1023/B:RISE.0000044597.10584.1a

Gvozdic, K., \& Sander, E. (2018). When intuitive conceptions overshadow pedagogical content knowledge: Teachers' conceptions of students' arithmetic word problem solving strategies. Educational Studies in Mathematics, 98(2), 157-175. https://doi.org/10.1007/s10649-018-9806-7

Kaltakci-Gurel, D., Eryilmaz, A., \& McDermott, L. C. (2016). Identifying pre-service physics teachers' misconceptions and conceptual difficulties about geometrical optics. European Journal of Physics, 37(4), 1-30. https://doi.org/10.1088/0143-0807/37/4/045705

Kukliansky, I., \& Eshach, H. (2014). Evaluating a Contextual-Based Course on Data Analysis for the Physics Laboratory. Journal of Science Education and Technology, 23(1), 108-115. https://doi.org/10.1007/s10956-013-9456-6

Kung, R. L. (2005). Teaching the concepts of measurement: An example of a concept-based laboratory course. American Journal of Physics, 73(8), 771-777. http://doi.org/10.1119/1.1881253 
Mallet, D. G. (2007). Multiple representations for systems of linear equations via the computer algebra system Maple. International Electronic Journal of Mathematics Education, 2(1), 16-32.

Marshall, J. A., \& Dorward, J. T. (2000). Inquiry experiences as a lecture supplement for preservice elementary teachers and general education students. American Journal of Physics, 68(S1), S27-S36. https://doi.org/10.1119/1.19516

Nivalainen, V., Asikainen, M. A., \& Hirvonen, P. E. (2013). Preservice teachers' objectives and their experience of practical work. Physical Review Special Topics - Physics Education Research, 9(1), 1-17. https://doi.org/10.1103/PhysRevSTPER.9.010102

Nivalainen, V., Asikainen, M. A., Sormunen, K., \& Hirvonen, P. E. (2010). Preservice and inservice teachers' challenges in the planning of practical work in physics. Journal of Science Teacher Education, 21(4), 393-409. https://doi.org/10.1007/s10972-010-9186-z

Nixon, R. S., Godfrey, T. J., Mayhew, N. T., \& Wiegert, C. C. (2016). Undergraduate student construction and interpretation of graphs in physics lab activities. Physical Review Physics Education Research, 12(1), 1-19. https://doi.org/10.1103/PhysRevPhysEducRes.12.010104

Ostermann, A., Leuders, T., \& Nückles, M. (2017). Improving the judgment of task difficulties: Prospective teachers' diagnostic competence in the area of functions and graphs. Journal of Mathematics Teacher Education, 21(6), 579-605. https://doi.org/10.1007/s10857-017-9369-z

Palic, G., \& Pirasa, N. (2012). A study of pre-service teachers' tendency for imprudent behaviour and physics laboratory attitudes. Procedia - Social and Behavioral Sciences, 47, 823-828. https://doi.org/10.1016/j.sbspro.2012.06.742

Pillay, S., Buffler, A., Lubben, F., \& Allie, S. (2008). Effectiveness of a GUM-compliant course for teaching measurement in the introductory physics laboratory. European Journal of Physics, 29(3), 647-659. https://doi.org/10.1088/0143-0807/29/3/024

Rollnick, M., Zwane, S., Staskun, M., Lotz, S., \& Green, G. (2001). Improving pre-laboratory preparation of first year university chemistry students. International Journal of Science Education, 23(10), 1053-1071. https://doi.org/10.1080/09500690110038576

Schnotz, W., \& Bannert, M. (2003). Construction and interference in learning from multiple representation. Learning and Instruction, 13(2), 141-156. https://doi.org/10.1016/S0959-4752(02)00017-8

Selçuk, G. S. (2011). Addressing pre-service teachers' understandings and difficulties with some core concepts in the special theory of relativity. European Journal of Physics, 32(1), 1. Retrieved from http://stacks.iop.org/0143-0807/32/i=1/a=001

Stavy, R., Babai, R., Tsamir, D., Tirosh, D., Lin, F. L., \& McRobbie, C. (2006). Are intuitive rules universal?. International Journal of Science and Mathematics Education, 4, 417-436. https://doi.org/10.1007/s10763-005-9012-9

Steinberg, R., \& Cormier, S. (2013). Understanding and affecting science teacher candidates' scientific reasoning in introductory astrophysics. Physical Review Special Topics - Physics Education Research, 9(2), 1-10. https://doi.org/10.1103/PhysRevSTPER.9.020111

Tirosh, D., \& Stavy, R. (1999). Intuitive rules: A way to explain and predict students' reasoning. Educational Studies in Mathematics, 38, 51-66. https://doi.org/10.1023/A:1003436313032

Zohar, A., \& David, A. Ben. (2008). Explicit teaching of meta-strategic knowledge in authentic classroom situations. Metacognition and Learning, 3(1), 59-82. https://doi.org/10.1007/s11409-007-9019-4

\section{Copyrights}

Copyright for this article is retained by the author(s), with first publication rights granted to the journal.

This is an open-access article distributed under the terms and conditions of the Creative Commons Attribution license (http://creativecommons.org/licenses/by/4.0/). 